\title{
Evaluation of the Astronomy Research Seminar
}

\author{
Rachel Freed ${ }^{1 *}$
}

\begin{abstract} research experience in the seminar.

\section{Keywords}

Evaluation - Student Research - Astronomy Research Seminar

${ }^{1}$ Institute for Student Astronomical Research, California, USA

${ }^{*}$ Corresponding author: r.freed2010@gmail.com
\end{abstract}

The need for a scientifically literate populace is clear now more than ever in recent human history as evidenced by global climate change and current political discourse and opining around it. Several decades of research and practice in science education still appear to leave much to be desired in terms of student understanding about the nature of science, scientific research and communication, and the need for scientific literacy. While there are potentially many avenues for students to pursue science in education and career paths, the Astronomy Research Seminar seems to have tapped into an intrinsic value in participating within and contributing to a Community-of-Practice as a way of learning. Based on an initial evaluation of students' experience and educational and career choices, the seminar has a meaningful impact on students. Furthermore, for many individuals it transforms their identities as scientists or at least budding-scientists and gives them a glimpse into the idea that they can participate in the scientific endeavor. As has been shown recently (Freed 2019) the seminar model is scalable as evidenced by the numerous variations that have developed over the past several years. This paper provides a deeper look into how students think and feel about their

\section{Introduction}

The Astronomy Research Seminar (ARS) is predicated on the philosophy and pedagogy around the value of learning within a Community-of-Practice (Wenger 1999; Genet et al. 2016, 2017). Within this framework, learning takes place as a Community with members ranging from the novice to the veteran, each learning from the other, and individuals are transformed by their learning and participation. The Astronomy Research Seminar and the Community-of-Practice in which it exists have both expanded significantly over the past several years. After initially being offered through Cuesta Community College in San Luis Obispo, CA, the seminar is now offered by numerous institutions and organizations throughout the country, either inperson or as a hybrid or totally online course. In its spread it has taken on several different forms over the years (Freed 2019).

The ARS is quite different from, and perhaps complementary to, general astronomy courses at the high school and college level, as it focuses on a very narrow field of study, with an emphasis on student-led research and publication. There are no prerequisites and the aim is not an accumulation of a large body of content knowledge, but rather a few specific research-oriented, collaborative, and communication-based skills. These are all meant to be widely applicable well outside the domain of astronomy and even of science itself, while con- 
temporaneously improving scientific literacy and understanding. Evaluation of such programs is critical to determining their value and outcomes as well as strategies for improvement.

There is a growing body of literature looking at changes in attitude, (Bartlett et al. 2018; Wittman 2009; Zeilik et al. 1999), learning gains (e.g. bailey2012development) and interest in astronomy resulting from participation in courses or research programs for students and/or educators. The emotional impacts of looking through a telescope, collecting one's own data and contributing to scientific knowledge, and the influence on learning and then educational and career choices is less well studied although becoming an important part of the literature. This is aided by the development of new validated instruments to measure attitudes (Bartlett et al. 2018) and self-efficacy in astronomy (Freed et al. prep). The work presented here aims to provide an initial evaluation of the astronomy research seminar's influence on students' understanding of scientific research, and their sense of self-efficacy within the Community-of-Practice.

\section{Evaluation}

\section{Data Collection}

Data was collected through online surveys, phone and video conference interviews, and student reflection papers as described below. One of the surveys is provided in Appendix A as an example.

\section{Surveys}

One hundred students in total have completed one of the six surveys given to students at different institutions. The ex-post-facto survey was sent to students who had been in the course previously, dating as far back as 2009, who were contacted through various means, including social media or connections they had maintained over the years. Of the nine participants who responded to the survey six were female and three were male. The BoyceAstro Survey was conducted when the students were all present at the final day of the seminar, thereby capturing data from a large percentage of the participants in those seminars. The rest of the surveys were embedded within the learning management system at the end of the online or hybrid courses in 2016 and 2017 and were optional for students. The questions from the ex-post-facto survey, Boyce Astro survey and Cuesta Spring 2017 surveys were almost identical, while the other three surveys were less extensive. Not all surveys asked for gender data. The survey statistics on the number of students, gender and school level when taking the seminar are summarized in Table 1 below.

\section{Interviews}

Interviews were conducted over Zoom video conferencing with eleven students and three instructors. The interviews were recorded and transcribed for analysis.

\section{Student Reflection Data}

One institution providing the astronomy research seminar had their students write up reflections in response to several questions about the seminar after having completed it instead of completing a survey. The eighteen reflection papers were analyzed here. It is important to note that this is a private, online high school for exceptionally advanced and self-motivated students. For example, numerous seventh and eighth graders successfully complete Advanced Placement courses at this school. Thus, this school represents a different demographic than many public community colleges.

In this research there were four main themes that interview and survey questions revolved around or that students brought up of their own accord. These were:

- The experience of doing scientific research

- The value of working in teams

- The importance of writing a paper for publication

- The impact of involvement within a Communityof-Practice

Each of these are addressed here. 


\begin{tabular}{|c|c|c|c|c|c|}
\hline \multirow{2}{*}{$\begin{array}{c}\text { Program and year of } \\
\text { course }\end{array}$} & \multirow{2}{*}{$\begin{array}{l}\text { Number of } \\
\text { student survey } \\
\text { respondents }\end{array}$} & \multicolumn{2}{|c|}{$\begin{array}{c}\text { Gender (when asked, } \\
\text { and provided) }\end{array}$} & \multicolumn{2}{|c|}{$\begin{array}{l}\text { School level when the seminar } \\
\text { was taken }\end{array}$} \\
\hline & & Female & Male & Undergraduate & High School \\
\hline $\begin{array}{c}\text { Students from 2009-2017, } \\
\text { Ex post facto }\end{array}$ & 9 & 6 & 3 & 5 & 4 \\
\hline Boyce Astro 2016-2018 & 57 & 28 & 28 & $\begin{array}{c}30 \\
\text { (2 post-college) }\end{array}$ & $\begin{array}{c}24 \\
(18 \text { th grade })\end{array}$ \\
\hline Cuesta Spring 2017 & 23 & $\mathrm{~N} / \mathrm{A}$ & N/A & 21 & 2 \\
\hline Cuesta Summer 2017 & 5 & $\mathrm{~N} / \mathrm{A}$ & N/A & 5 & 0 \\
\hline Cuesta Spring 2018 & 2 & N/A & N/A & 5 & 0 \\
\hline $\begin{array}{c}\text { InStAR Hybrid Summer } \\
2018\end{array}$ & 4 & $\mathrm{~N} / \mathrm{A}$ & N/A & 4 & 0 \\
\hline TOTAL & 100 & 34 & 31 & 72 & 31 \\
\hline
\end{tabular}

Figure 1. Distribution of survey responses, gender and school level when taking the seminar

\section{Data Analysis}

In the surveys and interviews one of the first questions was "How did the astronomy research seminar most benefit you?". This was put in first to elicit responses minimally influenced by ideas embedded in a more specific question such as the idea of teamwork in the question "Was there any value in working in teams?".

The nine students who responded to this particular survey gave the following answers:

- "Greatly improved my scientific writing skills. It was my first glimpse into the scientific process."

- "Made my college applications more interesting, and expanded my understanding of astronomy."

- "I learned how people create and submit research"

- "It introduced me into the world of scientific collaboration and publishing a scientific paper."

- "It introduced me to the idea of evidencebased research and the process of writing and submitting a research article."
- "I wish to become a professor, so I benefited from the experience of writing and publishing a paper"

- "Just an amazing process for learning"

- "Getting published"

- "Unsure."

This question has been asked of other seminar students and was reported on in Freed (2018). As was found in the previous study, the students feel that one of the most important aspects of the program is learning how to write a scientific paper. Forty four percent of the students here included "writing" or "scientific paper" in their answers, which is similar to the $45 \%$ shown in the earlier study of 23 participants.

\section{The Experience of Doing Scientific Research}

A key principle underlying the research seminar is that it provides, as much as possible, a genuine experience of the nature of professional science for students in the early part of their educational careers. The challenges include their lack of content knowledge, experience with conducting and managing research, and scientific writing. However, the seminar structure and requirements try to provide a framework in which this can all be addressed in 
the hopes that the student experience will be that of true scientists and that students will understand that they are scientists and can contribute meaningfully to the community. In Tables 2-5 showing survey data, the number of responses for each question is given in parentheses.

About two thirds of the students surveyed felt confident that the process they went through was similar to what professional scientists would do and that they were doing real research. Another $22 \%$ felt it was "somewhat" like what professionals do and $32 \%$ felt it was "somewhat" like real research. These combined numbers are similar to the $90 \%$ who felt that their research contributed at least in a small way to the scientific community. This is in stark contrast to general introductory science courses in college and most lab-based science courses in high school, where skills and content are taught but no new research is done.

\section{Student Reflections}

The question "Is the project you are doing changing your thoughts about what it means to do scientific research? Was it different than expected?" was posed. Out of the 18 students, 17 (94\%) stated that there were things about the research project that were different than they expected. The tone of each response, however, was very positive, overall.

Seven of the 18 students (39\%) commented that they now understand that scientific research is more difficult or more time-consuming than they had expected, although none of the student responses indicated they felt this was negative.

- "I never expected the data would be so difficult to analyze"

- “...now I realize the difficulty in actually doing the research"

- "This made me realize how time-consuming scientific research/writing is"

- "It is much harder and slower than I expected."

Of the 18 students, five (28\%) mentioned the importance and/or difficulty of the writing process as something new for them.
- "I also never realized how important papers really are. They are absolutely necessary and have to be constructed very carefully so that you can share your results."

- "I originally thought it was more out in the field, collecting data, and taking measurements, but this project has shown me that it is mostly looking at data, and working on your actual paper."

Most of the responses indicated that the students really enjoyed and valued their experience despite it being different than expected, and in many cases much more challenging.

- "The research feels like it does have an actual scientific value which is a good feeling."

- "We got to do research on the more fundamental level, and look at raw unprocessed data and draw conclusions ourselves. We are used to looking at Wikipedia and saying "This star has been identified as a quadruple star". Now we are able to draw those conclusions ourselves."

- "I'd also known that there were binary... systems... but it didn't really capture my interest until I looked at the systems, and graphed their orbits, and added my now-significant findings to the data. In short, this class is infinitely more awesome than I expected."

- "I have learned that students can be real researchers too."

It is an important point to note that not all the seminar students were on a science track. Many were already leaning in that direction, and for some it solidified their direction, while some who were not considering science ended up changing to a science track after having gone through the seminar.

\section{Working in Teams}

The astronomy research seminar requires that students work in teams as a pedagogical and philosophical approach. Not only is this representative of true 


\begin{tabular}{|l|c|c|c|}
\hline \multicolumn{3}{|c|}{ The experience of doing scientific research } \\
\hline $\begin{array}{l}\text { Do you feel that your team went through (at least } \\
\text { roughly) the same research process that professional } \\
\text { research teams go through? (86 responses) }\end{array}$ & Yes & Somewhat & Not at all \\
\cline { 2 - 4 } $\begin{array}{l}\text { Did the seminar make you feel like you were doing } \\
\text { real research, or did it seem mostly like an } \\
\text { academic lab class as in chemistry, biology, or } \\
\text { physics with known outcomes? (88 responses) }\end{array}$ & $\begin{array}{c}\text { Real Research that will } \\
\text { contribute to scientific } \\
\text { knowledge }\end{array}$ & $\begin{array}{c}\text { Somewhat like real } \\
\text { research }\end{array}$ & $\begin{array}{c}\text { Mostly like an academic } \\
\text { lab class }\end{array}$ \\
\cline { 2 - 4 } & $\mathbf{6 3}$ & 32 & 4 \\
\hline $\begin{array}{l}\text { Do you feel that your research contributed to the } \\
\text { scientific community? (99 responses) }\end{array}$ & Yes & $\begin{array}{c}\text { Yes, but only in a } \\
\text { minor way }\end{array}$ & $\begin{array}{c}\text { No, in the end it was just } \\
\text { another academic } \\
\text { exercise }\end{array}$ \\
\cline { 2 - 4 }
\end{tabular}

Figure 2. Percentage of student answers to survey questions relating to the experience of doing scientific research

scientific research, but the value that a diverse team with different experiences, skills and knowledge can bring to collaborative work is critically important for preparing students for the world beyond school and producing the highest quality work.

Community college students

- "Being a team researcher was amazing. It was something I had always wanted to do and something I hope to do more of in the future"

- "This was my first exposure to a team research group, so I was able to take a lot away from this process. I learned the aspect of project planning, management, and critical thinking during the first few weeks of the class when we were brainstorming about what our project could actually look like. I was also able to learn more about technical writing and editing during the research paper portion of this process"

- "I played team lead in this research. The initial responsibility to my team was intimidating at first, and it did not go away until the end of the course. I am fine with unequal workload, that's how life is, but all played an equal role in supporting the team."

High School
- "Team researching is actually pretty hard at first. You have to open your mind to ideas that might not be yours and still constantly suggest new ones. In addition, you need to say what you think about an idea without sounding too harsh about. Since there are two different views, adaptation is required. After a while though, you start thinking the same and this becomes easier and easier. [One of the students] doesn't seem to like research, so I have taken that role in my group."

Many students have commented on how much they learned about taking on a leadership role and learning about team management. A team of students from one Community College who went through the seminar in the summer of 2018 has already put together a team to do another research project more independently. It is common for students to become self-motivated once they understand that they can play an active role in true research.

\section{Student Reflections}

The question "What is it like being a team researcher? Is it different than laboratory classes you have taken?" was posed. One hundred percent of the students appreciated working as a team to do the research project. Interestingly some even commented on both the advantages as well as the challenges of working in teams but all of them felt it was beneficial. 


\begin{tabular}{|c|c|c|c|}
\hline \multicolumn{4}{|c|}{ Working in Teams } \\
\hline \multirow{2}{*}{$\begin{array}{l}\text { Did it work to have a team of student researchers or } \\
\text { would it have worked better to do the research on } \\
\text { your own? ( } 99 \text { responses) }\end{array}$} & The team was great. & The team was $\mathrm{OK}$. & $\begin{array}{c}\begin{array}{c}\text { I would rather work on } \\
\text { my own. }\end{array} \\
\end{array}$ \\
\hline & 73 & 20 & 7 \\
\hline \multirow{2}{*}{$\begin{array}{l}\text { Do you feel your team managed its own research, or } \\
\text { did the research supervisor actually run the show } \\
\text { for you? ( } 93 \text { responses) }\end{array}$} & $\begin{array}{l}\text { Yes, the team managed } \\
\text { its own research }\end{array}$ & $\begin{array}{l}\text { Sort of but the } \\
\text { research supervisor } \\
\text { helped a lot }\end{array}$ & $\begin{array}{l}\text { No, the research } \\
\text { supervisor managed } \\
\text { the research }\end{array}$ \\
\hline & 87 & 12 & 1 \\
\hline \multirow{2}{*}{$\begin{array}{l}\text { Did you feel that you were able to make real } \\
\text { choices, or was the path pretty well set in stone? ( } 86 \\
\text { responses) }\end{array}$} & $\begin{array}{l}\text { Our team developed its } \\
\text { own ideas and had } \\
\text { plenty of choices. }\end{array}$ & $\begin{array}{l}\text { There was some } \\
\text { choice }\end{array}$ & There were no choices. \\
\hline & 50 & 34 & 16 \\
\hline \multirow{2}{*}{$\begin{array}{l}\text { Do you feel that you were able to make a significant } \\
\text { contribution to your team's research project? ( } 88 \\
\text { responses) }\end{array}$} & Yes & Only marginally & No \\
\hline & 70 & 24 & 6 \\
\hline \multirow{2}{*}{$\begin{array}{l}\text { Did your contribution to your team's research make } \\
\text { you feel like you could contribute to teams in the } \\
\text { future? ( } 88 \text { responses) }\end{array}$} & Yes & Somewhat & Not really \\
\hline & 80 & 17 & 3 \\
\hline
\end{tabular}

Figure 3. Percentage of student answers to survey questions relating to working in teams

- "Being a team researcher is difficult but better I think than if I was researching on my own. It is good to be part of a team because everyone has different things they are good at, so altogether a group can be good at everything!"

- "Working as part of a team when doing research can be very useful for advancing the project quickly and in-depth...Also, teams allow for peer review of each other's work, and can provide a system of checks and balances to ensure the highest quality of work is produced."

- "Being a team researcher complicates and simplifies the project. Coordinating activities and work can be difficult....and finding the time to work together can be challenging... Working together simplifies things because there are more ideas brought to the table..."

- "I enjoy being a team researcher. The way we divide up the work really works for the group as a whole, because each member does what they feel comfortable doing."
- "I have enjoyed being a team researcher. Our team roles change each week based on what we need to accomplish and dividing the work has been a successful strategy for matching our strengths with various aspects of the project in addition to learning new skills."

These students really seem to understand the value of working as a team and leaning on individuals' strengths and they come to this realization through the research seminar. It was interesting to note the comments from one student who apparently is "that person", the one who ends up doing all the work in a traditional group project setting:

- "It's definitely different from any other projects I've done. In all the other projects, I was the person who did everything. If there was a paper, I knew everything that was in it, and where it all came from. It's a little bit weird to look at the document and find that everything changed."

\section{The Importance of Writing a Paper for Pub- lication}

The Astronomy Research Seminar is designed to allow half of the course for writing and rewriting the 
research paper. This often surprises students and new instructors until they have gone through the process and seen the challenges of preparing a truly publishable paper. The seminar developers have often thought that the amount of time and focus on writing might be off-putting to some students. However, feedback, survey and interview results over the years have shown this not to be the case. Rather, more often than not, the writing ends up being one of the greatest benefits that students report on. Furthermore, many students, in their reflections, interviews or survey answers, talked about the benefits of writing as a team where it lessened the individual writing load while allowing each student to focus on their particular strengths and interests.

Only 3\% of the students felt that the intense amount of writing made the seminar "less fun". Most students felt that the writing was a really good part of the experience and for many students learning how to write scientifically was one of the biggest benefits of the Astronomy Research Seminar.

- "The publication requirement, and the reviewing process especially, made sure that our writing was clear, concise, and that we weren't missing any information so that our results/analysis would make sense in the context of the paper."

\section{Student Reflections}

The question "How important is it to you to have a paper submitted for publication? How do you think being coauthor of a research paper might affect your career?" was posed. Twelve of the 18 students $(67 \%)$ mentioned that they thought it would be helpful for their career to have a published paper.

- "Having a research paper with my name is very important. Colleges will be impressed if I have a research paper that was published, and I want to get into prestigious colleges"

- "I would like to publish a paper and it is important to me. It might allow me to stand out as a scientist when I apply for college and gives me a competitive edge on knowing how real scientific research works."
Several of the students made the point that it was certainly not the reason they took the seminar, or it was less important than the research experience itself, or that contributing to the science was a bigger benefit.

- “...it will certainly look nice on my resume. I do however see more value in the content than in the credentials."

- "When I enrolled in this course, to me it was less important to have a paper submitted for publication, and more important to learn about astronomy and what astronomers do. While I find having a paper cool (especially for bragging rights), to me it is more important to learn about astronomy and how to manipulate the software."

- "I'm not doing this paper for the credentials I might get later in life, but rather because I actually want to contribute to the science community."

- "For me it isn't all that important in terms of big picture/career stuff. I want to submit a paper for publication because I have worked hard on it and want other people to see what our team has poured our energy and thought into. I joined this class because it sounded interesting, I enjoy astronomy, and Kalée is an incredible teacher. I did not join because I thought it would be important to have a paper published (even though that is INCREDIBLY cool and probably kind of helpful for potential future opportunities/applications to schools)"

Seven of the 18 (39\%) explicitly stated they didn't think it would help their careers or it was not that important to them to have a published paper.

- "It is not as important to me that the paper is submitted for publication as my peers, as I don't plan to go into the field..."

- "It is important to me because I think it would just be a SUPER SUPER SUPER amazing 


\section{The importance of writing and publishing a scientific paper}

With the advantage of hindsight, how important do you think it was that the seminar insisted on published results? (This question said "check all that apply", therefore the percentages add up to more than 100.)

\begin{tabular}{l}
\cline { 2 - 2 } \\
\cline { 2 - 2 }
\end{tabular}

When you realized how much careful writing scientists have to do, did this discourage you from thinking about becoming a scientist? (88 responses)

\begin{tabular}{|c|c|c|c|}
$\begin{array}{c}\text { Without the } \\
\text { publication } \\
\text { requirement the } \\
\text { seminar would not } \\
\text { have had much } \\
\text { benefit to me. } \\
\text { requirement really made } \\
\text { the seminar different than } \\
\text { any course I had taken } \\
\text { before then. } \\
\text { requirement } \\
\text { really sharpened } \\
\text { our team's } \\
\text { critical thinking. }\end{array}$ & $\begin{array}{c}\text { The publication } \\
\text { The publication } \\
\text { requirement took all } \\
\text { the fun out of the } \\
\text { seminar because we } \\
\text { had to spend most of } \\
\text { the time writing and } \\
\text { rewriting our } \\
\text { papers. }\end{array}$ \\
\hline $\mathbf{4 3}$ & 64 & 59 & 3 \\
\hline $\begin{array}{c}\text { Not at all; critical } \\
\text { careful writing is cool }\end{array}$ & Not really; writing is necessary & Yes, it discouraged me \\
\hline 93 & 5 & \multicolumn{2}{|c|}{5} \\
\hline
\end{tabular}

Figure 4. Percentage of student survey responses regarding the value of writing and publishing a scientific paper

thing to be able to do!!!!!!! But it wouldn't really affect my career as a ballet dancer at all."

Significantly, one student went so far as to explicitly state they were not yet a scientist. This particular reflection goes against the premise that having students do research, publish their work and become immersed in a Community-of-Practice will help them feel like they are scientists.

- “...our paper is probably going to be hidden in the far corner of some digital database (which is physically impossible) and not touched by anyone who has any sense of who to trust in terms of scientific papers. This will serve as an exercise, and if I ever become an actual scientist, these experiences will help me deliver my first "formal" paper."

\section{The Impact of Involvement within a Community-of-Practice}

"Learning is a matter of engagement: it depends on opportunities to contribute actively to the practices of communities that we value and that value us, to integrate their enterprises into our understanding of the world, and to make creative use of their respective repertoires." (Wenger 1999, p227)

Students in the Astronomy Research Seminar are explicitly taught the fundamental concepts of a Community-of-Practice as defined by Wenger (1999) and are encouraged to reach out and engage with experts outside of the course they are taking. For example, all student teams that have been through the seminar have contacted Dr. Brian Mason at the US Naval Observatory who curates the Washington Double Star Catalog to request past observations of the systems they are studying. Furthermore, teams are often connected to other people within the field who have experience in double star research, AstroImageJ expertise, or other areas in which they can assist students. Occasionally, outside instructors will join a team meeting to learn about the research seminar, and in this way students are temporarily playing an instructor role as someone, in this case, perhaps an experienced astronomy instructor, is learning from them. As Wegner points out, again in Communities of Practice: Learning, Meaning and Identity, "When old-timers and newcomers are engaged in separate practices, they lose the benefit of their interactions...Communities are thus deprived of the contributions of potentially the most dynamic, albeit inexperienced, segment of 
their membership - the segment that has the greatest stake in their future".

\section{Survey Data}

Ninety four percent of the students surveyed felt that they were at least somewhat immersed in a Community-of-Practice and all of the students surveyed found the external reviews of their paper at least somewhat helpful, if not very helpful in the writing process. Students were often enthralled with the idea that they could communicate directly with experts in the field, whether it was professional astronomers, software programmers or advanced amateurs with decades of experience researching and publishing their results on double stars. One example of this was a team that had a Skype meeting with Gianluca Sordiglioni (in Italy), the author of the Stelle Doppie double star online search engine. The team included information obtained directly from Sordiglioni in their published paper (Badami et al. 2018) and expressed excitement about the conversation and being able to get personal help from the program developer.

One of the many goals of the seminar is having students become immersed in a Community of Practice and to really learn the value of collaboration amongst themselves and with outside groups such as the wider astronomical community. Sometimes this was accomplished simply through discussion which led to them reaching out to experts in the field. Additionally, videos were created explicitly to explain to the students the value not only of collaboration but highlighting to them their role in the greater community. One example of this was that at the second annual Conference on Robotic Telescopes, Student Research, and Education (RTSRE): a community college instructor wanted to learn about the research seminar and sat in on the Zoom meeting being conducted with students and was able to get first-hand experience with how the seminar is conducted. Another example of how the seminar students are incorporated in the community was that as they were going through the seminar using Las Cumbres Observatory (LCO) telescopes this information was shared not only with Wayne Rosing, the founder of LCO, but also in the LCO Education Partner monthly meetings with LCO's Global director and education director of the telescopes so they were getting real-time feedback about how their partnership was impacting students. The students knew that astronomy professionals were aware of their work, which gave them an extra sense of pride and tangible connection to the Community-of-Practice of which they were a part.

\section{Impacting Students Lives}

Having sat in meetings with about a dozen different teams over the past four years it has been impressive to hear the responses and feedback from the majority of students who go through the various research seminars. For many it has helped guide their educational and career paths and for many it has influenced their understanding of the process of science, the value of communication and collaboration and the challenges of and appreciation for scientific writing. The sentiments expressed below are commonly heard in conversation among seminar students.

- "My team contributed some pretty amazing skills across the board and we produced absolute magic."

- "Once we were able to navigate through our communication issues, all team members contributed to the very best of their abilities...I am very proud of what we were able to accomplish together in such a short period of time and I would be honored to work with any of them again on future projects!"

- "I had an amazing experience with the...program, and would recommend it to anyone with a passion for astronomy. I learned so much from this seminar, and it helped me gain an understanding of how the scientific community worked. It also connected me with many different people with similar passions as me."

- "This class definitely gave me the fever for research. As a future scientist, the question 


\begin{tabular}{|l|c|c|c|}
\hline \multicolumn{4}{|c|}{ The Value of the community-of-Practice } \\
\hline $\begin{array}{l}\text { Did you feel immersed in a Community-of- } \\
\text { Practice? (88 survey responses) }\end{array}$ & Yes & Somewhat & No \\
\cline { 2 - 4 } & $\mathbf{5 6}$ & 39 & 6 \\
\hline $\begin{array}{l}\text { How helpful was the external review in improving } \\
\text { your team's paper? }\end{array}$ & Very helpful & Somewhat & Not at all \\
\cline { 2 - 4 } & $\mathbf{8 8}$ & 12 & 0 \\
\hline
\end{tabular}

Figure 5. Percentage of student answers to survey questions relating to working within a Community-of-Practice

of why is always on my mind. If I have the opportunity to participate in team research in the future, I will certainly take the leap."

Based on interviews, survey results, student reflections and the large number of students who have propagated the seminar at new institutions after their initial involvement, it is clear that this approach to education has far reaching impacts. Furthermore, the influence on individual students' lives, educations, and careers speaks to the power of the underlying pedagogical approaches of the seminar in having students take ownership and responsibility for their research, work in collaborative teams, and go through the rigorous process of learning to write quality scientific papers.

In the summer of 2018 a team of students and their instructor who had done the research seminar and published a paper had the opportunity to visit the Mount Wilson Observatory and the instructor gave the following feedback:

- "We had *such* a wonderful time at Mount Wilson-it was a mind-blowingly incredible and perfect day. So many of the students and parents told me that the experience was really transformative for them, and it was so much fun for me as well... Tom Meneghini and his amazing staff might just have created a few new scientists on Saturday!"

\section{Case Study: Mark Brewer}

Brewer took the seminar as a junior in college in 2011, resulting in his first of 13 publications
(Brewer 2011), and loved it so much he immediately started his own version which he provided for students from middle school up to college as well as the general public. Brewer has 13 Journal of Double Star Observations publications to his name, most of which include numerous students that he has brought into his weekend double star workshops.

When asked what kind of influence the seminar had on him, aside from the obvious influence in motivating him to hold his own workshops, he had a lot to say:

- "It was showing how much hands-on experience was big in the workforce. Having the piece of paper [publication] helps out but most organizations [and] government programs they want to see that you actually have some hands-on experience. That means a lot. Obviously, the piece of paper means a lot too, but I saw that the hands-on experience was important... I was able to go from an intern to a full-time employee and I currently still only hold an associate's degree... I'm going on five years in an atmospheric program and I was an intern for almost two years in an astronomy program."

In response to the statement "It sounds like you would almost credit the research seminar with giving you an understanding of the importance of the hands-on experience", Brewer replied,

- "Yes. And the publications. That was big too because that showed that, overall, I could do the hands-on part of science. I was overall a 
scientist and the engineering type...there are a lot of open doors too."

Brewer has held five workshops with a total of about 70 participants who all learned to collect and analyze data and write a scientific paper for publication.

When asked "Was your ability or confidence in your ability to [do scientific research and publish] influenced by the seminar?", Brewer responded,

- "Oh definitely. When I came up for my internship here, we were using JPL's electrical communication program and I was running a solar differential imaging motion monitor and a 14-in Schmidt-Cassegrain telescope on a fork mount with a wedge. And that's exactly what I used [in the seminar]. I was using an 8-inch, but it was the exact same thing, just scaled up. They didn't have to teach me how to run the telescope."

Brewer has expressed a high level of self-efficacy, not only in doing double star research, but in applying skills he learned in the program in diverse settings, including his employment. Additionally, by running his own seminars he has acted upon a strong sense of self-efficacy in the teaching aspects of the research program. Brewer has written about and presented his double star research program at the Society for Astronomical Sciences Annual Symposium (Brewer et al. 2014).

\section{Case Study: The Growth of a Scientist, Men- tor and Researcher}

One particular seminar participant was the kind of student who was not interested in school, earning his GED and leaving high school early with mediocre interest in education. After ten years in retail he decided to go back to school, unsure about what to study or what his interests were. In his first year as an undergraduate at a community college, he was taking physics and, in his words, "I bumped into Irena Stojimirovic, an astronomy 101 professor at Mesa College who introduced me to the Boyce program...My academics have accelerated since being introduced to this program." He participated in the Astronomy Research Seminar through Miramar College in San Diego and has been mentoring students in the program for the two years since then. After presenting his research at the first RTSRE Conference in 2017, he put a lot of effort into considering what to present at the 2nd RTSRE conference that would have true scientific value and meaning to the community.

- "The thing we are most stressed about is actually doing something that's worthwhile of presentation and that also meets the standards of inquiry which is what I think the whole conference is revolving around."

He reflected,

- "Some of the students were trying to form fit their results into a model that their teacher gave them rather than taking unexpected results and interpreting on the fly. Last year gave me a heck of a lot of understanding on how you ask these sorts of questions, the perspective that I should take when coming at it from a professional educator and a researcher point of view vs the students point of view. Since the [RTSRE] conference I have mentored a few different students."

When asked about the eight student teams he's mentored he replied

- "Over the past three semesters all of them have published papers. I really want to highlight that it's a personal goal for me, each semester I want the teams to add a new bit of flavor or a new layer of research to what they have done. [Student $\mathrm{x}$ ], he didn't just do a measure and report paper; he also did a Speckle Interferometry paper with Richard Harshaw. He worked with Richard Harshaw on his own motivation to do something that was outside the recommended criteria provided to us by Boyce... [He] found something that was really fascinating to him and he asked the question, 'What do I need to 
do this?' [The instructors said] 'we know somebody. Let me put you in contact with him and see what you can do.' That first semester [Student x] busted out a Speckle paper. Last [year] I had two students who focused on doing Common Proper motion analysis on both of their papers. Every paper last semester...had a Common Proper Motion analysis integrated into it. What's the point for students who are taking higher end physics classes and are trying to get into a STEM field to ask the same questions that are already being asked? If you want to know more there's a possibility... let's figure out how to do it. Each semester there are a few students who flake off...but other ones who take the whole project and run with it with the motivation that makes me feel inspired and left in awe."

This former student epitomizes a student who has become fully integrated into the Community-ofPractice and transformed his identity as a scientist as well as his educational and career path. He is thinking critically not only about the astronomy research but about the educational aspects as well. As Wenger (1999) states in his book Communitiesof-Practice "Learners must be able to invest themselves in communities of practice in the process of approaching a subject matter. Unlike in a classroom, where everyone is learning the same thing, participants in a community of practice contribute in a variety of interdependent ways that become material for building an identity. What they learn is what allows them to contribute to the enterprise of the community and to engage with others around that enterprise" (Wenger (1999); p 271). This student has certainly invested himself in the Community and transformed his identity as a scientist, researcher and life-long learner.

\section{Case Study: From a San Diego Community College to New Mexico Tech}

One premise of the astronomy research seminar is that it changes lives and changes students' identities as scientists. One of numerous examples of the wide-ranging impact of the seminar is in the story of a community college student who first took the seminar in the Fall of 2016 through the Boyce-Astro program in San Diego. After having published two papers during the semester-long seminar, when he transferred to New Mexico Tech he immediately began mentoring students from there as they went through the online version of the seminar. In addition, he helped to run the first annual RTSRE Conference in June of 2017, and presented his research there. In an interview in April 2018, he stated

- "my question...was where do you go from the end of the seminar? Is it enough to get people interested in the field and then expect them to go about their own path?"

And about having been through the seminar he stated

- "It definitely cemented my direction. It gave me just enough of a taste to want to do more...I was on the fence between particle physics and astrophysics...but this pushed me to one side. And so, I guess, to answer my own question, maybe it is enough to be introduced to the meat and potatoes, so to speak, of astronomy".

What stands out about this interview was the thoughtfulness and scientific questioning this student went through in considering both science and educational research about science. He proceeded to then do a study on the influence of the astronomy research seminar on other students, all while working on a degree in astrophysics at New Mexico Tech. This is another example of a seminar student who, after being immersed within the Communityof-Practice, has invested himself fully within it.

\section{Impacting Teachers' Lives}

The educators who take on the research seminar themselves and then bring their students on board have a transformative experience through the process. As high school science teachers generally don't have experience in conducting and publishing 
scientific research, this program can be as powerful for them as for the students in identifying themselves as scientists. Additionally, it transforms their approach to science teaching in philosophy and pedagogy. Kalee Tock (2019) of Stanford OHS has written about the experience stating

- "I found myself reflecting often on the scientific process and the ways in which actual research differs from the picture we paint for students in introductory science classes...in real science you have to be open to pursuing other paths than the one upon which you originally set out. The experiments that we do in most of our science classes run counter to this because we grade students on their answers to a specific question."

She continues

- "While the place of student innovation in classroom lab experiments is limited at best, this sort of inventiveness plays a huge role in the scientific enterprise. Real, impactful science depends on scientists' being ready to intentionally study different, more interesting questions than the ones they set out to ask...But, we do them a disservice in pretending that the cycle of hypothesis - data conclusion they follow in traditional lab experiments mimics the way science is actually done."

In an interview Ms. Tock described how, after having been a teacher for over a decade, it was through conducting the research seminar for two semesters that she finally feels like she is a subject matter expert in this area due to her research experience with the students over the course of the year. In addition to the direct impact on her students of providing a research and publication experience, she has integrated herself fully within the Communityof-Practice, presenting talks and workshops at the first and second annual RTSRE conferences as well as other national conferences. She has also provided opportunities for her students to present at these conferences, enabling them to become integrated into the larger Community.

\section{Conclusion and Future Directions}

The astronomy research seminar, in its various forms over the past $10+$ years has had a significant impact on the STEM pathways of many students, in addition to being an identity-transforming experience for many. One of the biggest indicators of how students are inspired or transformed by this research experience early in their education (pregraduate school) is the many offshoot programs and advanced research projects the students themselves have created, as well as the way many of them have become fully integrated into the larger Communityof-Practice, helping to run conferences, edit conference proceedings, and guide other students through the research experience themselves.

While there are many students for whom the experience was not as transformative and life-changing, most of them feel that it was a great experience, different from any other courses or opportunities they have had in school, even as an undergraduate science major. Having sat in on about a dozen research seminars over the past four years and interacted with scores of students within the seminars, the author of this paper has heard time and again how exciting it is for students to do this kind of research, go through the team-work development process, write a paper (even through many iterations), and to then have their research published.

Many educators from middle school through community college and from all parts of the country are looking for ways to include research or provide research opportunities for their students (personal communications) and the Astronomy Research Seminar is an impactful and scalable way to achieve this. Combined with the effort to improve science literacy and participation in STEM fields in this country, the Astronomy Research Seminar strives to provide transformative experiences in scientific research for students, giving them the opportunity to become part of a larger community. Feedback from this and future evaluations will enable modifications to the existing programs as well as new ones as they spring up, hopefully helping to create a society of citizens knowledgeable about the processes of science and scientific communication 
and fully aware of their importance for our global community.

\section{Acknowledgments}

This study was funded in part by NSF grant 1610350 . The author would like to thank Michael Fitzgerald and Russell Genet for their invaluable feedback, and Carol Zink for her detailed and thoughtful review of this paper.

\section{References}

Badami, U. A., Tock, K., Carpenter, S., Kruger, K., Freed, R., and Genet, R. M. (2018). Measurement of the Position Angle and Separation of HJ 1924. Measurement, 14(1).

Bartlett, S., Fitzgerald, M. T., McKinnon, D. H., Danaia, L., and Lazendic-Galloway, J. (2018). Astronomy and Science Student Attitudes (ASSA): a short review and validation of a new instrument. Journal of Astronomy \& Earth Sciences Education (JAESE), 5(1):1-22.

Brewer, M. (2011). Astrometric Measurements of the Double Star STFA 43AB. JDSO, 7(2):107108.

Brewer, M., Weise, E., Estrada, R., Estrada, C., Buehlman, W., Wasson, R., Rogers, A., and Camunas, M. (2014). Apple Valley Double Star Workshop. Journal of Double Star Observations, 10(2).

Freed, R. (2018). The Astronomy Research Seminar: The Wide-Ranging Impact on Student Education and Careers. Preliminary Results. Society for Astronomical Sciences, 37:161-173.

Freed, R. (2019). Astronomy Research Seminar Expansion and Building a Community-of-Practice. RTSRE Proceedings, 2(1).

Freed, R., McKinnon, D., Fitzgerald, M., Reichart, D., and Norris, C. (in prep). Development and Validation of an Astronomy Self-Efficacy Instrument for knowing and doing.
Genet, R., Armstrong, J., Blanko, P., Boyce, G. B., Brewer, M., Buchheim, R., Calanog, J., Castaneda, D., Chamberlin, R., Clark, R. K., et al. (2017). Student Scientific Research within Communities-of-Practice. In Society for Astronomical Sciences Annual Symposium, volume 36, pages 143-150.

Genet, R., Johnson, J., Boyce, P., Boyce, G., Harshaw, R., Kenney, J., Collins, D., Rowe, D., Brewer, M., Estrada, R., et al. (2016). A StudentCentered Astronomical Research Community of Practice. SASS, 35:59-74.

Tock, K. (2019). Astronomy, Technology, and the Scientific Method: Reflections on the Astronomy Research Seminar at Stanford Online High School, Spring 2018. RTSRE, 2(1).

Wenger, E. (1999). Communities of practice: Learning, meaning, and identity. Cambridge university press.

Wittman, D. (2009). Shaping attitudes toward science in an introductory astronomy course. The Physics Teacher, 47(9):591-594.

Zeilik, M., Schau, C., and Mattern, N. (1999). Conceptual astronomy. II. Replicating conceptual gains, probing attitude changes across three semesters. American Journal of Physics, 67(10):923-927. 